\title{
Front Matter: Volume 8916
}

, "Front Matter: Volume 8916," Proc. SPIE 8916, Sixth International Symposium on Precision Mechanical Measurements, 891601 (10 October 2013); doi: 10.1117/12.2041466

SPIE Event: Sixth International Symposium on Precision Mechanical

SPIE. Measurements, 2013, Guiyang, China 


\title{
Sixth International Symposium on \\ Precision Mechanical \\ Measurements
}

\author{
Shenghua Ye \\ Yetai Fei \\ Editors
}

\section{8-12 August 2013 \\ Guiyang, China}

Organized by

Hefei University of Technology (China)

Coorganized by

Beijing Information Science \& Technology University (China)

Guiyang Xintian Oetech Company, Ltd. (China)

Zhejiang Sci-Tech University (China)

Harbin Institute of Technology (China)

Sponsored by

ICMI-International Committee on Measurements and Instrumentation

NSFC - National Natural Science Foundation of China (China)

CIS-China Instrument and Control Society (China)

Cooperating Organization and Publisher

SPIE

\section{Volume 8916}

Part One of Two Parts 
The papers included in this volume were part of the technical conference cited on the cover and title page. Papers were selected and subject to review by the editors and conference program committee. Some conference presentations may not be available for publication. The papers published in these proceedings reflect the work and thoughts of the authors and are published herein as submitted. The publisher is not responsible for the validity of the information or for any outcomes resulting from reliance thereon.

Please use the following format to cite material from this book:

Author(s), "Title of Paper," in Sixth International Symposium on Precision Mechanical Measurements, edited by Shenghua Ye, Yetai Fei, Proceedings of SPIE Vol. 8916 (SPIE, Bellingham, WA, 2013) Article CID Number.

ISSN: 0277-786X

ISBN: 9780819497925

Published by

SPIE

P.O. Box 10, Bellingham, Washington 98227-0010 USA

Telephone +1 3606763290 (Pacific Time) · Fax +1 3606471445

SPIE.org

Copyright @ 2013, Society of Photo-Optical Instrumentation Engineers.

Copying of material in this book for internal or personal use, or for the internal or personal use of specific clients, beyond the fair use provisions granted by the U.S. Copyright Law is authorized by SPIE subject to payment of copying fees. The Transactional Reporting Service base fee for this volume is $\$ 18.00$ per article (or portion thereof), which should be paid directly to the Copyright Clearance Center (CCC), 222 Rosewood Drive, Danvers, MA 01923. Payment may also be made electronically through CCC Online at copyright.com. Other copying for republication, resale, advertising or promotion, or any form of systematic or multiple reproduction of any material in this book is prohibited except with permission in writing from the publisher. The CCC fee code is 0277-786X/13/\$18.00.

Printed in the United States of America.

Publication of record for individual papers is online in the SPIE Digital Library.

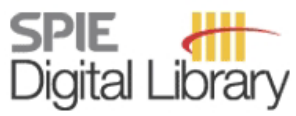

SPIEDigitalLibrary.org

Paper Numbering: Proceedings of SPIE follow an e-First publication model, with papers published first online and then in print and on CD-ROM. Papers are published as they are submitted and meet publication criteria. A unique, consistent, permanent citation identifier (CID) number is assigned to each article at the time of the first publication. Utilization of CIDs allows articles to be fully citable as soon as they are published online, and connects the same identifier to all online, print, and electronic versions of the publication. SPIE uses a six-digit CID article numbering system in which:

- The first four digits correspond to the SPIE volume number.

- The last two digits indicate publication order within the volume using a Base 36 numbering

system employing both numerals and letters. These two-number sets start with 00, 01, 02, 03, 04, $05,06,07,08,09,0 A, 0 B \ldots$. 0Z, followed by 10-1Z, 20-2Z, etc.

The CID Number appears on each page of the manuscript. The complete citation is used on the first page, and an abbreviated version on subsequent pages. Numbers in the index correspond to the last two digits of the six-digit CID Number. 


\section{Contents}

xvii Conference Committee

xxi Introduction

\section{SIXTH INTERNATIONAL SYMPOSIUM ON PRECISION MECHANICAL MEASUREMENTS}

891602 Nondestructive optical characterization of MEMS [8916-236]

R. J. Pryputniewicz, Worcester Polytechnic Institute (United States)

891603 Traceability of measurements at the nanoscale [8916-222]

H. Bosse, Physikalisch-Technische Bundesanstalt (Germany)

891604 Adaptive fractional differential method based on CSGV to extract image texture feature [8916-166]

A. Song, W. Wang, Southeast Univ. (China)

891605 Development of transmission error tester for face gears [8916-233]

Z. Shi, X. Lu, C. Chen, J. Lin, Beijing Univ. of Technology (China)

891606 Computational metrology for nanomanufacturing [8916-27]

S. Liu, Huazhong Univ. of Science and Technology (China)

891607 An experiment of femtosecond laser absolute distance measurement by spectrally resolved interferometry [8916-42]

W. Zhou, Academy of Opto-Electronics (China); Y. Li, Academy of Opto-Electronics (China) and Huazhong Univ. of Science and Technology (China); R. Ji, Academy of OptoElectronics (China); Y. XU, Academy of Opto-Electronics (China) and Huazhong Univ. of Science and Technology (China); D. Liu, Huazhong Univ. of Science and Technology (China)

891609 Dimensional measurement of micrometer-scale structures with a nanopipette ball probe by using shear-force detection [8916-215]

S. Ito, I. Kodama, W. Gao, Tohoku Univ. (Japan)

89160 A Development of a miniature multi-degree-of-freedom measurement system for ultraprecision stages [8916-14]

H.-Y. Wang, B.-H. Liao, M.-J. Chou, Y.-Y. Tseng, K.-C. Fan, National Taiwan Univ. (Taiwan, China)

$8916 \mathrm{OB} \quad$ Using acceleration measurements and neuro-fuzzy systems for monitoring and diagnosis of bearings [8916-181]

T.-I. Liu, California State Univ. Sacramento (United States) and National Taipei Univ. of Technology (Taiwan, China); J. Lee, P. Singh, California State Univ. Sacramento (United States); G. Liu, Mori Seiki Manufacturing USA, Inc. (United States) 
8916 OC Nanometrology interferometric coordinates measurement system for local probe microscopy [8916-10]

J. Hrabina, J. Lazar, Institute of Scientific Instruments (Czech Republic); P. Klapetek, Czech Metrology Institute (Czech Republic); O. Cip, M. Cizek, M. Sery, Institute of Scientific Instruments (Czech Republic)

8916 OD Review and comparison of temporal- and spatial-phase shift speckle pattern interferometry for 3D deformation measurement [8916-235]

X. Xie, L. Yang, X. Chen, N. XU, Oakland Univ. (United States); Y. Wang, Hefei Univ. of Technology (China)

$89160 \mathrm{E}$ Analysis and experimental study of the spherical joint clearance [8916-79]

P. Zhao, P. Hu, X. Bao, S. Li, Hefei Univ. of Technology (China)

8916 OF Characteristics of the higher-order resonant cantilever in dynamic atomic force microscopy [8916-211]

Y. Zhao, Hefei Univ. of Technology (China) and Anhui Jianzhu Univ. (China); Q. Huang,

K. Shi, H. You, H. Xie, Hefei Univ. of Technology (China)

8916 OG Key errors analysis and simulation of a 3-PUU parallel CMM [8916-71]

S. Li, S. Li, P. Zhao, P. Hu, Hefei Univ. of Technology (China)

$8916 \mathrm{OH}$ Measurement uncertainty analysis on laser tracker combined with articulated CMM [8916-234]

H. Zhao, L. Yu, Y. Du, H. Zhang, Hefei Univ. of Technology (China)

8916 Ol Variable stiffness and damping semi-active vibration control technology based on magnetorheological fluids [8916-202]

S. Zhao, H. Deng, J. Zhang, Hefei Univ. of Technology (China); S. Sun, Hefei Univ. of Technology (China) and Univ. of Wollongong (Australia); L. Wang, Hefei Univ. of Technology (China)

8916 0J Three-dimensional reconstruction coordinate error induced by asynchronous cameras for moving objects [8916-187]

Y. Wang, J. Zhang, H. Deng, R. Fan, Hefei Univ. of Technology (China)

8916 OK Surface roughness measurement based on digital laser speckle pattern by Markov Random Fields Model in wavelet domain [8916-157]

L. Yang, R. Lu, L. Lei, Z. Liu, Hefei Univ. of Technology (China); Y. Shi, Huainan Union Univ. (China); L. Lei, Z. Liu, Hefei Univ. of Technology (China)

$8916 \mathrm{OL}$ The optimal design for measurement systems based on uniform accuracy life [8916-146] Z.-Y. Cheng, X.-H. Chen, R. Li, Hefei Univ. of Technology (China); M. Jiang, Zhejiang Normal Univ. (China); Y. Fei, Hefei Univ. of Technology (China)

$89160 \mathrm{M}$ Evaluation of measurement uncertainty based on Bayesian information fusion [8916-77] S. Wang, X. Chen, Q. Yang, Hefei Univ. of Technology (China)

8916 ON A robust sinusoidal signal processing method for interferometers [8916-61] X. Wu, H. Zhang, Hefei Univ. of Technology (China); Y.-Y. Tseng, National Taiwan Univ. (Taiwan, China); K.-C. Fan, Hefei Univ. of Technology (China) and National Taiwan Univ. (Taiwan, China) 
891600 DSPI system based on spatial carrier phase shifting technique [8916-231]

Y. Wang, J. Li, J. Sun, Hefei Univ. of Technology (China); L. Yang, Hefei Univ. of Technology (China) and Oakland Univ. (United States)

8916 OP Elastic mechanism design of a CMM contact probe [8916-121]

R.-J. Li, Hefei Univ. of Technology (China) and Anhui Electrical Engineering Professional Technique College (China); K.-C. Fan, Hefei Univ. of Technology (China) and National Taiwan Univ. (Taiwan, China); H. Zhou, N. Wang, Q. Huang, Hefei Univ. of Technology (China)

$89160 Q$ Measurement of transient surface temperatures during rubbing using infrared thermography [8916-172]

T. You, J. YU, X. Yu, Hefei Univ. of Technology (China)

8916 OR A designed circuit for sintering optical fiber probe [8916-200]

Z. Ai, S. Dong, Q. Yang, N. Lin, Y. Xu, Hefei Univ. of Technology (China)

8916 OS Optimization of BRDF measurement method using Spectralon white reflectance standard [8916-58]

H.-R. Tao, X.-H. QU, F.-M. Zhang, Y.-Q. Zhu, Tianjin Univ. (China)

8916 OT An indirect accuracy calibration and uncertainty evaluation method for large scale inner dimensional measurement system [8916-12]

B.-L. Liu, X.-H. QU, Tianjin Univ. (China)

$89160 \mathrm{U}$ The combined measurement and compensation technology for robot motion error [8916-49]

R. Li, X. QU, Y. Deng, B. Liu, Tianjin Univ. (China)

8916 OV Fiber optic interferometer fringe projector using sinusoidal phase-modulating [8916-167]

C. LV, F. Duan, F. Zhang, X. Duan, E. Bo, F. Feng, Tianjin Univ. (China)

8916 OW Simulation and signal analysis of Akiyama probe applied to atomic force microscope [8916-78]

L. Wang, Tianjin Univ. (China); M. Lu, National Institute of Metrology (China); T. Guo, Tianjin Univ. (China); S. Gao, H. Zhang, National Institute of Metrology (China)

8916 OX Phase modulation dynamic AFM measurement system based on tuning fork probe [8916-91]

T. Guo, W. Chen, Z. Wu, J. Chen, X. Fu, X. Hu, Tianjin Univ. (China)

8916 OY Design and finite element analysis of the vibration isolation system of STM [8916-238]

Y. Liu, X. Fu, L. Xu, Y. Song, Tianjin Univ. (China)

891602 An effective signal separation and extraction method using multi-scale wavelet decomposition for phase-sensitive OTDR system [8916-151]

H. Wu, X. Li, H. Li, Y. Wu, Y. Gong, Y. Rao, Univ. of Electronic Science and Technology (China) 
891610 Analysis of the forces in electrostatic force microscopy for profile measurement of microstructured surface of dielectric [8916-73]

G. He, Chongqing Univ. of Science and Technology (China) and Tohoku Univ. (Japan);

Z. Jia, S. Ito, Y. Shimizu, W. Gao, Tohoku Univ. (Japan)

891611 A kinematic parameter calibration method for articulated arm coordinate measuring machine [8916-114]

S. Zhao, L. Zhu, Q. Chen, Z. Pan, Y. Guo, Beijing Information Science \& Technology Univ. (China)

891612 Technique of laser confocal and Raman spectroscopy for living cell analysis [8916-13] X. Meng, L. Zhu, Beijing Information Science \& Technology Univ. (China)

891613 All-fiber Q-switched ytterbium-doped fiber laser in MOPA configurations [8916-147] W. He, Hefei Univ. of Technology (China); L. Zhu, Hefei Univ. of Technology (China) and Beijing Information Science \& Technology Univ. (China); Y. Zhang, M. Dong, Beijing Information Science \& Technology Univ. (China); X. Chen, Hefei Univ. of Technology (China)

891614 Harmonic distortion analysis of a Mach-Zehnder intensity modulator [8916-208] $X$. Zhang, Beijing Information Science \& Technology Univ. (China); S. Hu, Beijing Univ. of Aeronautics and Astronautics (China); Y. Jia, Z. Zhou, L. Liao, Beijing Information Science \& Technology Univ. (China)

891615 Design of high current voltage conversion circuit based on LT3743 [8916-203]

G. Cai, X. Lou, Y. Zhang, Y. Na, Q. Liu, Beijing Information Science \& Technology Univ. (China)

891616 Structure parameters optimization and system simulation of a double-triangulation probe [8916-132]

D. Cheng, X. Lou, Q. Liu, M. Dong, Beijing Information Science \& Technology Univ. (China)

891617 Dynamic measurement of deformation using Fourier transform digital holographic interferometry [8916-188]

X. Gao, S. WU, L. Yang, Beijing Information Science \& Technology Univ. (China)

891618 Research on amplification and peak-holding circuits of nanosecond light pulse [8916-193] H. Liu, Y. Zhang, Y. Na, Beijing Information Science \& Technology Univ. (China)

891619 An improved centroid location algorithm for Infrared LED feature points [8916-137]

S. Wang, B. Yan, M. Dong, J. Wang, P. Sun, Beijing Information Science \& Technology Univ. (China)

8916 1A Simulation research of acousto optic modulator drive based on Multisim [8916-160] S. Wang, Y. Guo, L. Zhu, Y. Na, Y. Zhang, Q. Liu, Beijing Information Science \& Technology Univ. (China)

8916 1B An accuracy evaluating method for image point location based on linear fitting [8916-124] L. XU, M. Dong, J. Wang, P. Sun, Beijing Information Science \& Technology Univ. (China) 
8916 1C Quasi-distributed temperature sensor system based on various-packaged FBG [8916-199] Y. Zhang, Q. Liu, Beijing Information Science \& Technology Univ. (China); W. He, Hefei Univ. of Technology (China); L. Zhu, Beijing Information Science \& Technology Univ. (China)

8916 1D Optical tweezers based on cylindrical vector beams [8916-169]

Y. Xu, Z. Zhou, X. Zhang, Z. Zhao, L. Zhu, Beijing Information Science \& Technology Univ. (China)

$89161 \mathrm{H} \quad$ Measuring the lens focal length by laser confocal technique [8916-128] H. Wu, J. Yang, L. Qiu, W. Zhao, Beijing Institute of Technology (China)

$89161 \mathrm{~F}$ A method for extracting feature points of micro-calibration sample [8916-197] Y. Niu, J. Pan, X. Wang, Beijing Information Science \& Technology Univ. (China)

$89161 \mathrm{G}$ A variable weighted centroid method for retro reflective target locating [8916-103] W. Zhuang, M. Dong, P. Sun, J. Wang, Beijing Information Science \& Technology Univ. (China)

$89161 \mathrm{H} \quad$ Digital approach to stabilizing optical frequency combs and beat notes of CW lasers [8916-83]

M. Čížek, O. Číp, R. Šmíd, J. Hrabina, B. Mikel, J. Lazar, Institute of Scientific Instruments (Czech Republic)

891611 Calibration of elongation of fiber Bragg gratings by laser interferometer [8916-82] B. Mikel, M. Cizek, Institute of Scientific Instruments (Czech Republic); M. Holik, Brno Univ. of Technology (Czech Republic); O. Cip, Institute of Scientific Instruments (Czech Republic)

$89161 \mathrm{~J}$ Interferometry with suppression of fast fluctuations of the refractive index of air for nanometrology [8916-28]

J. Lazar, M. Hola, J. Hrabina, Z. Buchta, O. Cip, Institute of Scientific Instruments (Czech Republic)

$89161 \mathrm{~K}$ The investigation of electrolytic surface roughening for PCB copper foil [8916-239] S.-J. Lee, C.-K. Liu, Yuan Ze Univ. (Taiwan, China)

$89161 \mathrm{~L} \quad$ A three-degree-of-freedom hybrid vibration isolation system using adaptive proportional control supported by passive weight support mechanism [8916-230]

Y.-H. Liu, W.-H. Wu, C.-L. Chu, Southern Taiwan Univ. of Science and Technology (Taiwan, China)

$89161 \mathrm{M}$ Development of a micro-CMM with scanning touch probe and high-precision coplanar platform [8916-195]

C.-L. Chu, C.-T. Lu, H.-L Chen, J.-S. Ke, C.-M. Chang, Southern Taiwan Univ. of Science and Technology (Taiwan, China)

$89161 \mathrm{~N}$ The performance of an inspection system for indium tin oxide circuits by using a PDLC/ITO film [8916-54]

C.-H. Chan, National Tsing Hua Univ. (Taiwan, China); Y.-T. Zou, C.-T. Chen, T.-K. Liu, C.-H. Chen, H.-W. Wang, Industrial Technology Research Institute (Taiwan, China); S.-C. Lin, National Tsing Hua Univ. (Taiwan, China) 
891610 Optimizing the structure of a four-axis polarized scattering instrument using a double-loop approach [8916-50]

C.-J. Shih, Tamkang Univ. (Taiwan, China); T.-L. Teng, Hsiuping Univ. of Science and

Technology (Taiwan, China); Y.-A. Huang, Tamkang Univ. (Taiwan China)

8916 1P Optical magnetic field sensor improved by NdFeB ferromagnetic film [8916-62]

T. G. Nguyen, X. Jiao, W. Lei, Y. Ma, L. Ma, Univ. of Shanghai for Science and Technology

(China); B. Qian, Suzhou Institute of Nano-tech and Nano-bionics (China)

8916 1Q Structure design and characteristic analysis of micro-nano probe based on six dimensional micro-force measuring principle [8916-72]

H. Yang, C. Cai, C. Fang, T. Wu, Anhui Univ. of Technology (China)

8916 IR Research and analysis of AC sampling standard value converting circuits [8916-127]

L. Mu, Z. Li, Z. Chen, Anhui Univ. of Science and Technology (China)

8916 is Research on the working characteristic of Hall current sensor and the "modeling-deviation compensation" algorithm [8916-206]

L. Mu, Z. Chen, Z. Li, Anhui Univ. of Science and Technology (China)

8916 IT Multimodal image registration based on SURF and KD tree [8916-177]

Y. Yin, Z. Gu, C. Du, Anhui Univ. of Chinese Medicine (China)

8916 IU Study on real-time elevator brake failure predictive system [8916-56]

J. Guo, J. Fan, Beijing Univ. of Technology [China]

$89161 \mathrm{~V}$ Data repair method in incomplete free-surface measurement [8916-31]

Z. Wang, Q. Li, H. Yan, Q. Wang, BeiHang Univ. (China)

8916 IW Radial pressure sensor of sucker rod based on LabVIEW [8916-33]

Z. Wang, H. Yan, Q. Li, BeiHang Univ. (China)

8916 1X FPGA-based signal processing method of automatic interference comparator [8916-34]

Z. Wang, H. Chang, BeiHang Univ. (China); H. Gao, X. Ye, National Institute of Metrology (China)

$89161 Y$ Digital image correlation method for measuring thermal deformation of composite materials [8916-47]

L. Jiang, Y. He, D. Wang, K. Liu, Beijing Aerospace Institute for Metrology and Measurement Technology (China); W. Wu, Lunar Exploration and Aerospace Engineering Ctr. (China)

891612 Experimental research on anti-vibration interferometry based on time-frequency-domain analysis [8916-179]

Y. Hu, Q. Hao, F. Zhang, Y. Tian, Beijing Institute of Technology (China)

891620 Fast filtering of surface topography of micro-optics using non-local means [8916-153]

X. Zhang, H. Zhang, X. He, M. XU, Fudan Univ. (China)

891621 Uncertainty evaluation for a three dimensional rotary measuring system by Markov chain Monte Carlo method [8916-150]

B. Chen, X. Zhang, H. Zhang, X. He, M. XU, Fudan Univ. (China) 
891622 Feasibility study of detection of chatter by using FBG during boring [8916-182]

P. Y. Zhu, Guangzhou Univ. (China); W. Peng, L. Yuan, Z. J. Hu, Hunan Univ. of Science and Technology (China)

\section{Part 2}

891623 Radius measurement using a parallel two-step spatial carrier phase-shifting common-path interferometer [8916-94]

B. Hao, M. Diao, Z. Zhong, M. Shan, Y. Zhang, Harbin Engineering Univ. (China)

891624 Image edge enhancement for moving objects with a spiral phase filter [8916-100]

S. Bao, M. Shan, Z. Zhong, B. Hao, C. An, Harbin Engineering Univ. (China)

891625 3D measurement method based on combined temporal encoding structured light [8916-174]

X. Yu, Y. Wang, S. Yu, H. Cheng, X. Sun, S. Yu, D. Chen, Harbin Univ. of Science and Technology (China)

891626 Research of temperature field measurement using a flexible temperature sensor array for robot sensing skin [8916-149]

Y. Huang, S. Wu, R. Li, Q. Yang, Y. Zhang, C. Liu, Hefei Univ. of Technology (China)

891627 Dual AFM probes alignment based on vision guidance [8916-108]

H. Zhang, Hefei Univ. of Technology (China); S. Gao, Hefei Univ. of Technology (China) and National Institute of Metrology (China); M. Lu, L. Wang, National Institute of Metrology (China)

891628 A high-accuracy signal processing algorithm for frequency scanned interferometry [8916-70]

S. Zhang, Hubei Univ. of Technology (China); L. Yang, X. Wang, Z. Zhai, W. Liu, Hubei Univ. of Technology (China) and Key Lab. of Modern Manufacture Quality Engineering (China)

891629 Study on the three-station typical network deployments of workspace measurement and positioning system [8916-46]

Z. Xiong, Hubei Univ. of Technology (China); J. G. Zhu, B. Xue, S. H. Ye, Tianjin Univ. (China); Y. Xiong, Yunnan Sanhuan Sinochem Chemical Co. (China)

8916 2A Positioning method for a visual guiding system in a laser welding machine [8916-65] T. He, Y. Fan, Y. Xie, Q. Wu, Hubei Univ. of Technology (China)

8916 2B Numeric character recognition method based on fractal dimension [8916-44]

T. He, Y. Xie, J. Chen, L. Cheng, Y. Yuan, Hubei Univ. of Technology (China)

8916 2C Measurement error analysis of the 3D four-wheel aligner [8916-173]

Q. Zhao, D. Huang, T. Yang, X. Ding, Hunan Univ. of Science and Technology (China) 
8916 2D Optimized design of a band-pass filter with low frequency and narrow bandwidth [8916-171]

B. Tian, G. Fu, X. Liao, Hunan Univ. of Science and Technology (China); H. Cheng, Hunan Univ. of Science and Technology (China) and Institute of Geology and Geophysics (China); G. Li, Hunan Univ. of Science and Technology (China)

$89162 \mathrm{E}$ An apparatus for non-contact measuring profile of precision rotor based on laser triangulation [8916-170]

X. Yin, T. Yang, Q. Zhao, D. Huang, Hunan Univ. of Science and Technology (China)

$89162 \mathrm{~F} \quad$ Mine rescue capsule dynamics modeling and stress analysis [8916-180]

S. Yang, J. Li, Y. Sun, Hunan Univ. of Science and Technology (China)

$89162 \mathrm{G}$ A new thin-wall beam modal testing method based on single point laser continuous plane scanning vibration measurement [8916-68]

J. Wu, B. Qin, X. Li, Q. Zhao, Hunan Univ. of Science and Technology (China)

$89162 \mathrm{H}$ Self-adaptive grain recognition of a diamond grinding wheel and its grains assessment [8916-115]

C. Cui, L. Zhou, Q. Yu, H. Huang, R. Ye, Huaqiao Univ. (China)

891621 Correction on the effect of numerical aperture in optical scatterometry [8916-25]

W. Li, S. Liu, C. Zhang, X. Chen, H. Gu, Huazhong Univ. of Science and Technology (China)

$89162 \mathrm{~J}$ Optical character and calibration of 3D vision sensor [8916-156]

F. Liang, G. Liu, X. He, H. He, J. Shi, H. Zhang, Nanchang Univ. (China) and Nanchang

Propersasia Optolectronic Sci-Tech Dev. Co. (China)

8916 2K Design of PSD based solar direction sensor [8916-148]

G. XU, Z. Zhong, B. Wang, R. Guo, Y. Tian, Nanjing Univ. of Aeronautics and Astronautics (China)

$89162 \mathrm{~L}$ Smooth sliding mode control with a disturbance observer for a virtual axis parallel mechanism [8916-102]

D. Jiang, Z. Wang, Z. Wang, X. Zhang, Ningbo Technical College (China)

$89162 \mathrm{M}$ Simulation and design of a fiber Bragg grating flow sensor [8916-221]

Q. Jiang, F. Gao, Shandong Univ. (China)

$89162 \mathrm{~N}$ Design and study of a vibrating string accelerometer based on fiber Bragg grating [8916-223]

Q. Jiang, M. YU, L. Sun, Shandong Univ. (China)

891620 Placement of the material temperature sensor during measuring the accuracy of CNC machine tools [8916-178]

D. Zhao, M. Jia, J. Zhang, L. Sun, W. Li, Shandong Institute of Metrology (China)

8916 2P Aberration measurement for progressive addition lens based on Hartmann-Shack Sensor [8916-89]

L. Zhu, J. Chen, J. Xu, H. Pan, H. Zhang, S. Zhuang, Univ. of Shanghai for Science and Technology (China) 
$89162 \mathrm{Q}$ A study on the quality of micro-hole of Ti-6Al-4V by EDM process with on-machine measurement techniques [8916-48]

J. Li, X. Liu, X. Wei, S. Zhao, Sichuan Univ. (China)

$89162 R \quad$ A regression-based approach to tolerance values forecasting in micro/meso-scale for micro non-monolithic components [8916-29]

X. Liu, X. Wei, J. Li, S. Zhao, Sichuan Univ. (China)

891625 Soil water evaporation measurement of lysimeter based on fiber Bragg grating sensor [8916-140]

K. Yan, J. Liu, L. Miao, L. Bai, W. Zhong, Xi'an Univ. of Technology (China)

8916 2T Retrieval of aerosol size distribution based on GCV regularization with optical data of lidar [8916-21]

H. Zhao, Xi' an Univ. of Technology (China) and Beifang Univ. of Nationalities (China);

D. Hua, H. Di, Y. Wang, H. Zhao, Xi' an Univ. of Technology (China); J. Mao, Beifang Univ. of Nationalities (China)

$89162 \mathrm{U}$ Pulse modulation method for LED lidar light source [8916-36]

W. Zhong, J. Liu, D. Hua, F. Wang, K. Yan, Xi'an Univ. of Technology (China)

$89162 \mathrm{~V}$ Design of dual wavelength micro pulse polarization lidar system [8916-53]

Y. Song, D. Hua, S. Li, Y. Wang, W. Xin, H. Di, Xi'an Univ. of Technology (China)

8916 2W A novel Retinex algorithm based on alternating direction optimization [8916-37]

X. Fu, Q. Lin, W. Guo, Y. Huang, D. Zeng, X. Ding, Xiamen Univ. (China)

8916 2X Dynamic model of liquid copper temperature based on weighted LS-SVM [8916-17]

Y. Li, L. Ye, H. Guan, W. Zhong, X. Ma, Zhejiang Univ. (China)

$89162 Y$ Design of energy-saving control system for LED street lamps [8916-75]

X. Ding, W. Jin, Zhejiang Univ. (China)

$89162 Z$ Spectrum measurement for LED-based spectrum-tunable source [8916-159]

N. Jia, Zhejiang Univ. (China) and Hangzhou Vocational and Technical College (China);

Z. Zheng, Y. Yang, H. Wang, Zhejiang Univ. (China)

891630 Noise reduction of laser scanning data based on self-estimated angular threshold [8916-90]

Y. Wu, Zhejiang Univ. (China); W. Wang, K. Lu, Hangzhou Dianzi Univ. (China); Y. Wei,

Z. Chen, Zhejiang Univ. (China)

891631 Research status and developing trends of grating nanometer measuring technology [8916-57]

M. Jiang, H. Li, X. Wang, J. Shen, Zhejiang Normal Univ. (China)

891632 Roundness measuring instrument for 2-dimensional standards [8916-131]

W. Wang, National Institute of Metrology (China)

891633 Vibration criteria for vibration-sensitive laboratory based on intrinsic microseism [8916-242]

C. Cai, B. Zhou, J. Li, National Institute of Metrology [China] 
891634 Development and measurement of single layer thickness standard [8916-16]

J. Cui, Tianjin Univ. (China) and National Institute of Metrology (China); S. Gao, H. Du,

X. Zhu, National Institute of Metrology (China); L. Yan, Zhejiang Sci-Tech Univ. (China)

891635 Critical dimensional linewidth calibration using UV microscope and laser interferometry [8916-161]

Q. Li, S. Gao, W. Li, M. Lu, National Institute of Metrology (China); M. Zhang, Hefei Univ. of Technology (China)

891636 Bearing fault diagnosis based on scale-transformation stochastic resonance [8916-45]

Y. Cui, J. Zhao, T. Guo, Y. Song, China Jiliang Univ. (China)

891637 A dedicated on-line detecting system for auto air dryers [8916-93]

C. Shi, Z. Luo, China Jiliang Univ. (China)

891638 Detection technology research on the one-way clutch of automatic brake adjuster [8916-22]

W. Jiang, Z. Luo, Y. Lu, China Jiliang Univ. (China)

891639 Measurement system for characterizing surface friction properties of textile materials [8916-192]

B. Yao, Y. Yang, Z. Zhang, L. Yan, China Jiliang Univ. (China)

8916 3A Key techniques of ultra-precision aerostatic system [8916-117]

D. Li, J. Li, T. Cui, J. Hu, Y. Cheng, M. Wang, China Jiliang Univ. (China)

8916 3B ROIC with on-chip sigma-delta AD converter for HgCdTe e-APD FPA [8916-11]

G. Chen, Shanghai Institute of Technical Physics (China) and Univ. of Chinese Academy of Sciences (China); J. Zhang, Shanghai Institute of Technical Physics (China); P. Wang, J. Zhou, L. Gao, Shanghai Institute of Technical Physics (China) and Univ. of Chinese Academy of Sciences (China); R. Ding, Shanghai Institute of Technical Physics (China)

8916 3C Multi-beam synchronous measurement based on PSD phase detection using frequencydomain multiplexing [8916-198]

Y. Duan, L. Qin, L. Xuan, F. Xi, J. Mao, Chongqing Univ. (China)

$89163 \mathrm{~F} \quad$ A novel design of parallel piezoelectric six-degree-of-freedom accelerometer [8916-158] H. Lv, L. Qin, J. Liu, Chongqing Univ. (China)

$89163 \mathrm{G}$ Transformation method from incremental angular displacement sensors to absolute angular displacement sensors [8916-185]

F. Zheng, Chongqing Univ. of Technology (China)

8916 3H Dynamic high-speed acquisition system design of transmission error with USB based on LabVIEW and FPGA [8916-35]

Y. Zheng, Y. Chen, Chongqing Univ. of Technology (China)

891631 Dynamic self-calibration of time grating sensors based on self-adaptive Kalman filter algorithm [8916-184]

Z. Chen, Chongqing Univ. of Technology (China) 
8916 3J Error analysis and modeling for the time grating length measurement system [8916-63] Z. Gao, J. Fen, F. Zheng, Z. Chen, D. Peng, X. Liu, Chongqing Univ. of Technology (China)

8916 3K An improved SURF descriptor based on sector area partitioning [8916-92] L. Zeng, Y. Zhai, X. Fang, Academy of Equipment (China)

$89163 \mathrm{~L} \quad$ Kinematic modeling and simulation of articulated arm coordinate measuring machines based on MCPC method [8916-165]

J. Lu, G. Gao, Kunming Univ. of Science and Technology (China)

$89163 \mathrm{M}$ Development of automobile tyre lateral runout measurement sensor [8916-229]

X. Ma, Ningbo Dahongying College (China); L. Ye, G. Yao, D. Wang, Zhejiang Univ.

(China); X. Zhi, Zhejiang Univ. (China) and Anhui Univ. (China)

$89163 \mathrm{~N} \quad$ A novel DSSS based ToF measurement method for short baseline and its application in sound velocimeter [8916-67]

S. Zhao, Y. Wang, C. Qiao, C. Zhou, National Univ. of Defense Technology (China)

891630 Transmitting pulse signal design for ultrasonic time of flight measurement in short baseline framework [8916-15]

S. Zhao, Y. Wang, C. Qiao, C. Zhou, National Univ. of Defense Technology (China)

$89163 \mathrm{P}$ Precise ultrasonic ranging based on pseudo-random sequence modulated continuous signal processing [8916-142]

C. Qiao, Z. Huang, C. Zhou, National Univ. of Defense Technology (China)

$89163 Q$ A robust data fusion scheme for integrated navigation systems employing fault detection methodology augmented with fuzzy adaptive filtering [8916-43]

M. Ushaq, J. Fang, BeiHang Univ. (China)

8916 3R Design of scrap copper separation control system based eddy current sensor [8916-226]

D. Wang, Zhejiang Univ. (China) and Taiyuan Univ. of Science and Technology (China);

X. Ma, L. Ye, G. Yao, Zhejiang Univ. (China); S. Zhang, Zhejiang Univ. (China) and Taiyuan Univ. of Science and Technology (China)

891635 The 3D visualization technology research of submarine pipeline based Horde3D GameEngine [8916-227]

G. Yao, X. Ma, G. Chen, L. Ye, Zhejiang Univ. (China)

8916 3T LED uniform illumination system for DMD-based confocal microscopy [8916-81]

K. Xiao, W. Hou, Q. XU, B. Peng, Univ. of Shanghai for Science and Technology (China)

$89163 \mathrm{U}$ Research on direct calibration method of eye-to-hand system of robot [8916-118]

X. Hu, K. Xie, T. Peng, Hunan Univ. of Science and Technology (China)

8916 3V 3D reconstruction of surface based on binocular vision [8916-189]

X. Hu, T. Peng, K. Xie, Hunan Univ. of Science and Technology (China)

$89163 \mathrm{~W}$ A study on the fabrication of main scale of linear encoder using continuous roller imprint method [8916-98]

S. Fan, Y. Shi, L. Yin, L. Feng, H. Liu, Xi'an Jiaotong Univ. (China) 
$89163 X$ Study on technology of double parallel-joints coordinate measuring machine [8916-207] G. Xia, C. Liao, R. YU, Y. Fu, Nanchang Hangkong Univ. (China)

$89163 Y$ Three-dimensional shape measurement based on a combination of gray-code and phase-shift light projection [8916-66] Z. Wang, Y. Fu, J. Yang, G. Xia, J. Wang, Nanchang Hangkong Univ. (China)

891632 An improving demodulation of interferometric fiber optic sensor technology [8916-205] L. Gao, Huainan Union Univ. (China); Y. Li, Z. Chu, Hefei Univ. of Technology (China); M. Wu, China Electronics Technology Group Corp. (China); N. Lin, Hefei Univ. of Technology (China)

891640 Digital optimeter based on linear CCD [8916-116] Q. Hu, Y. Xu, Guiyang Xintian OETECH Co., Ltd. (China)

891641 Research on working clearance optimization for non-contact stress detection with magneto-elastic stress sensor [8916-213]

Y. Guo, G. Tang W. Wang, Hunan Univ. of Science and Technology (China)

891642 Arbitrary and absolute length measurement based on time-of-flight method using femtosecond optical frequency comb [8916-80]

S. Xing, F. Zhang, Tianjin Univ. (China); S. Cao, National Institute of Metrology (China);

X. QU, Tianjin Univ. (China)

891643 The accuracy analysis of the intersection measurement on the moving ships [8916-24] M. Wang, Q. Shan, K. Liu, Xi'an Institute of Optics and Precision Mechanics (China)

891644 Extending the measuring range of fiber optic displacement sensor with differential evolution optimized extreme learning machine [8916-110]

$X$. Wang, M. Ye, M. Jiang, Zhejiang Normal Univ. (China)

891645 Image measurement technique on vibration amplitude of ultrasonic horn [8916-55] Y. Zhang, Z. Wu, J. Zhu, J. He, G. Liu, Institute of Machinery Manufacturing Technology (China)

891646 Study on detection method of inner wall of small-diameter workpiece based on cone reflector [8916-228]

W. Lu, Shanghai Jiao Tong Univ. (China); Y. Yao, C. Li, Shanghai Institute of Spaceflight Control Technology (China); X. Chen, Shanghai Jiao Tong Univ. (China); L. Shen, Shanghai Institute of Spaceflight Control Technology (China); L. Lei, W. Sun, Shanghai Institute of Measurement and Testing Technology (China)

891647 A verification device for the stylus profilometer sensor [8916-246]

L. Guo, X. Liu, L. Zhou, W. Lu, W. Zhong, Huazhong Univ. of Science and Technology (China); Y. Luo, Wuhan Marine Machinery Plant Co., Ltd. (China)

$891648 \quad$ A small angle dynamic measuring device [8916-247]

J. Wang, X. Liu, W. Lu, L. Chen, Y. Zou, Huazhong Univ. of Science and Technology (China)

891649 Comprehensive evaluation of surface topography in running-in wear process [8916-248]

G. Zhang, X. Liu, W. Lu, Huazhong Univ. of Science and Technology (China) 
8916 4B Research on pre-processing of QR Code [8916-250]

H. Sun, H. Xia, N. Dong, Hefei Univ. of Technology (China)

Author Index

Proc. of SPIE Vol. $8916891601-15$

Downloaded From: https://www.spiedigitallibrary.org/conference-proceedings-of-spie on 26 Apr 2023 Terms of Use: https://www.spiedigitallibrary.org/terms-of-use 
Proc. of SPIE Vol. $8916891601-16$

Downloaded From: https://www.spiedigitallibrary.org/conference-proceedings-of-spie on 26 Apr 2023 Terms of Use: https://www.spiedigitallibrary.org/terms-of-use 


\section{Conference Committees}

Honorary Committee

G. F. Jin, Member of CAE/Tsinghua University (China)

B. H. Lu, Member of CAE/ Xi'an Jiaotong University (China)

Z. H. Zhang, Member of CAE/National Institute of Metrology (China)

S. H. Ye, Member of CAE/Tianjin University (China)

J. H. Su, Member of CAE/Kunming Institute of Physics (China)

Y. T. Fei, Hefei University of Technology (Chairman) (China)

Z. Li, Huazhong University of Science and Technology (China)

Q. S. Han, Beijing Information Science \& Technology University (China)

C. K. Chen, National Cheng Kung University (Taiwan, China)

K. Z. Fan, National Taiwan University (Taiwan, China)

Y. Chugui, Russian Academy of Sciences (Russia)

G. B. Wang, National Natural Science Foundation (China)

Conference Committee

Shenghua Ye, Conference Chair, Tianjin University (China)

Yetai Fei, Conference Chair, Hefei University of Technology (China)

G. F. Jin, Honorary Conference Chair, Member of CAE/Tsinghua University (China)

International Committee

Zh. You, Tsinghua University (China)

H. Bosse, Physikalisch-Technische Bundesanstalt (Germany)

R. J. Pryputniewicz, Worcester Polytechnic Institute (United States)

S. W. Kim, KAIST (Korea)

W. Gao, Tohoku University (Japan)

H. C. Fu, Metal Industries Research and Development Centre (Taiwan, China)

G. Jaeger, Ilmenau University of Technology (Germany)

R. Leach, National Physical Laboratory (United Kingdom)

Y. J. Lin, University of Akron (United States)

Kuangzhao Fan, National Taiwan University (Taiwan, China)

T. I. Liu, California State University at Sacramento (United States)

Y. Zhang, SIMTech (Singapore)

W. H. Li, University of Wollongong (Australia)

Program Committee

Kuangzhao Fan, Chair, Taiwan University (Taiwan, China) 
Zh. You, Chair, Tsinghua University (China)

Y. S. Gao, Co-chair, Hong Kong University of Science \& Technology (China)

S. L. Zhang, Co-chair, Tsinghua University (China)

D. Butler, Nanyang Technological University (Singapore)

M. Chang, Chung Yuan Christian University (Taiwan, China)

L. X. Yang, Oakland University (United States)

L.-C. Chen, Taipei University of Technology (Taiwan, China)

C. F. Cheung, Hong Kong Polytechnic University (China)

L. D. Yu, Hefei University of Technology (China)

M. Krystek, Physikalisch-Technische Bundesanstalt (Germany)

S. Kurokawa, Kyushu University (Japan)

P. Ott, University of Heilbronn (Germany)

Y. F. Li, City University of Hong Kong (Hong Kong, China)

S. C. Lin, National Tsing Hua University (Taiwan, China)

H. J. Pahk, Seoul National University (Korea)

Y. Shimizu, Hitachi Company (Japan)

G. Y. Tian, University of Newcastle upon Tyne (United Kingdom)

J. X. Yang, Zhejiang University (China)

J.-Y. Yen, National Taiwan University (Taiwan, China)

Z. Y. Shi, Beijing University of Technology (China)

W. H. Zhou, Chinese Academy of Science (China)

H. Bosse, Physikalisch-Technische Bundesanstalt (Germany)

R. J. Pryputniewicz, Worcester Polytechnic Institute (United States)

S. W. Kim, KAIST (Korea)

W. Q. Zhao, Beijing Institute of Technology (China)

W. Gao, Tohoku University (Japan)

H. C. Fu, Metal Industries Research Development Centre

(Taiwan, China)

G. Jaeger, Ilmenau University of Technology (Germany)

R. Leach, National Physical Laboratory (United Kingdom)

Y. J. Lin, University of Akron (United States)

H. P. Huang, National Taiwan University (Taiwan, China)

T. I. Liu, California State University at Sacramento (United States)

Y. Zhang, SIMTech (Singapore)

W. H. Li, University of Wollongong (Australia)

\section{Organizing Committee}

L. D. Yu, Chair, Hefei University of Technology (China)

L. Q. Zhu, Co-chair, Beijing Information Science and Technology University (China)

B. Y. Chen, Co-chair, Zhejiang Sci-Tech University

(China)

R. S. Lu, Hefei University of Technology (China)

Q.X. Huang, Hefei University of Technology (China)

P. H. Hu, Hefei University of Technology (China) 
W. S. Li, Hefei University of Technology (China)

H. X. Deng, Hefei University of Technology (China)

H. J. Xia, Hefei University of Technology (China)

J. Zhang, Hefei University of Technology (China)

Z. M. Zeng, Tianjin University (China)

X. H. Qu, Tianjin University (China)

H. Zhao, Shanghai Jiaotong University (China)

J. R. Chu, University of Science and Technology of China (China)

A. G. Song, Southeast University (China)

W. H. Zhou, Academy of Opto-Electronics (China)

D. L. Peng, Chongqing Institute of Technology (China)

X. K. Liu, Chongqing Institute of Technology (China)

M. L. Dong, Beijing Information Science \& Technology University (China)

Z. Luo, China Jiliang University (China)

\section{Conference Secretariat}

L. D. Yu, Secretary-General, Hefei University of Technology (China)

M. Y. Kuang, Hefei University of Technology (China)

Q. Y. Liu, Hefei University of Technology (China)

Y. Du, Hefei University of Technology (China)

Session Chairs

1 Micro-Nano Metrology \& MEMS

H. Bosse, Physikalisch-Technische Bundesanstalt (Germany)

Q.X. Huang, Hefei University of Technology (China)

2 Coordinate Measurement Technology

L. D. Yu, Hefei University of Technology (China)

Zhao-yao Shi, Beijing University of Technology (China)

3 Sensor Technology and Application

L. X. Yang, Oakland University (United States)

L. Q. Zhu, Beijing Information Science \& Technology University (China)

4 Online Automatic Measurement and Control

P. H. Hu, Hefei University of Technology (China)

S. W. Kim, KAIST (Korea)

5 Vibration, Stress and Thermal Measurement

R. J. Pryputniewicz, Worcester Polytechnic Institute (United States)

Josef Lazar, Academy of Sciences of the Czech Republic

(Czech Republic) 
6 Optical Metrology: Image Processing

S. Ito, Tohoku University (Japan)

Q. Hao, Beijing Institute of Technology (China)

7 Measurement Signal Analysis and Processing

T. I. Liu, California State University at Sacramento (United States)

H. X. Deng, Hefei University of Technology (China)

8 Quality Engineering and Uncertainty Evaluation

A. G. Song, Southeast University (China)

M. Chang, Chung Yuan Christian University (Taiwan, China)

9 Optical Metrology: Optical Probe and System

W. H. Zhou, Chinese Academy of Science (China)

B. Y. Chen, Zhejiang Sci-Tech University (China) 


\section{Introduction}

With the development of science and technology and the improvement of the requirement in machinery manufacturing, most countries in the world have put lots of human and material resources into the field of mechanical engineering precision measurement research. New methods, new technology and new equipment appear thick and fast. Under this background, we have successfully held five sessions of International Symposium on Precision Mechanical Measurement (ISPMM). The subject and the major topics include length and angular measurement, coordinate measurement technology, micro-nano metrology and MEMS, sensor technology and application, online automatic measurement and control vibration, stress and thermal measurement, optoelectronic measurement and image processing, measurement signal analysis and processing, precision theory and uncertainty evaluation, quality engineering theory and technology and so on. The 6th ISPMM conference was held in Guiyang, August 8-12, and the theme of the conference was "New century, new technology and new development." More than 150 manuscripts were submitted to our conference, and over 200 registered delegates participated in the conference.

Yetai Fei Shenghua Ye 
Proc. of SPIE Vol. $8916891601-22$

Downloaded From: https://www.spiedigitallibrary.org/conference-proceedings-of-spie on 26 Apr 2023 Terms of Use: https://www.spiedigitallibrary.org/terms-of-use 